\title{
Causes of death of professional musicians in the classical genre
}

\author{
Kuusi, Tuire
}

2019-06

Kuusi , T , Haukka , J , Myllykangas , L \& Järvelä , I 2019 , ' Causes of death of professional musicians in the classical genre ', Medical Problems of Performing Artists, vol. 34 , no. 2 , pp. 92-97 . https://doi.org/10.21091/mppa.2019.2016

http://hdl.handle.net/10138/321470

https://doi.org/10.21091/mppa.2019.2016

unspecified

acceptedVersion

Downloaded from Helda, University of Helsinki institutional repository.

This is an electronic reprint of the original article.

This reprint may differ from the original in pagination and typographic detail.

Please cite the original version. 


\section{The causes of death of professional musicians in the classical genre}

Tuire Kuusi $^{1}$, Jari Haukka ${ }^{2}$, Liisa Myllykangas ${ }^{3}$, Irma Järvelä ${ }^{4}$

${ }^{1}$ Tuire Kuusi, Prof, Sibelius Academy, University of the Arts, Helsinki, Finland

${ }^{2}$ Jari Haukka, PhD, The Department of Public Health, University of Helsinki

${ }^{3}$ Liisa Myllykangas, MD, PhD, Department of Pathology, University of Helsinki and Helsinki University Hospital, Helsinki, Finland

${ }^{4}$ Irma Järvelä, MD, PhD, Department of Medical Genetics, University of Helsinki, Finland

Correspondence:

Irma Järvelä, $\mathrm{MD}, \mathrm{PhD}$

Department of Medical Genetics

Biomedicum

Haartmaninkatu 8

University of Helsinki

00251 Helsinki, Finland

irma.jarvela@helsinki.fi

GSM 358505447030 


\section{Abstract}

Objective Music practice has been reported to have favourable effects on human health. To obtain more information about the effect of exposure to music from early childhood, we examined the causes of death of professional musicians in the classical genre.

Methods We used the standardized mortality ratios (SMR) for Finnish performing artists $(\mathrm{N}=$ 5,780) and church musicians $(\mathrm{N}=22,368)$ during 1981-2016. We examined the deaths from cardiovascular diseases, cancers, neurodegenerative and alcohol-related diseases. The diagnoses were based on the ICD-10, and the data were obtained from Statistics of Finland.

Results Overall, SMR for all-cause mortality was 0.59 (95\% CI: $0.57-0.61)$ for church musicians and 0.75 (95\% CI: $0.70-0.80)$ for performing artists, suggesting a protective effect of music for health. In contrast, we found increased mortality in alcohol-related diseases among female performing artists (SMR 1.85, 95\% CI: 1.06-2.95) and in neurodegenerative diseases among male performing artists (1.46; 95\% CI: 1.13-1.84). Additionally, we found higher SMRs for female than male church musicians for cancers $\left(\mathrm{SMR}_{\text {females }} 0.90 ; 95 \% \mathrm{CI}\right.$ : $0.83-0.97$; $\left.\mathrm{SMR}_{\text {males }} 0.6095 \% \mathrm{CI}: 0.54-0.67\right)$ and cardiovascular diseases $\left(\mathrm{SMR}_{\text {females }} 0.75 ; 95 \% \mathrm{CI}\right.$ : 0.68-0.82; SMR males $0.58 ; 95 \%$ CI: $0.54-0.64)$.

Conclusions Our results show that the causes of death differ among professional musicians in classical genre. Performing artists are not protected from neurodegenerative diseases or alcohol-related deaths. The study calls for further study on the working life of musicians.

Keywords: standard mortality rate, SMR, professional musician, classical genre 


\section{Section 1: The scientific knowledge on the topic before}

- music listening and practice has been shown to affect human brain structure and function, and have beneficial effect on human health

- empirical data is largely missing about the effects of music on human bodies

\section{Section 2: What this study adds}

- Our study suggests that music practice does not prevent from dementia

- Studies on the life-long effects of profession in music are required 


\section{Introduction}

Practicing music is a complex cognitive activity requiring simultaneous auditory and visual perception skills, precise timing and extended control over motor behaviour. There is abundant evidence that music listening and practice affect human brain structure and function. ${ }^{1-3}$ Listening to music has been shown to cause physiological changes in cerebral blood flow, cardiovascular and muscle function, and enhance dopamine secretion in the human brain. ${ }^{12}$ Musical practice has also shown to improve cognitive performance. ${ }^{4}$ There are various brain areas that are activated during playing; especially those processing auditory, visual, and motor information, but also those involved in emotions, attention, learning and memory. ${ }^{2356} \mathrm{~A}$ large number of studies in the literature show that music has beneficial effects on human health, ${ }^{7}$ and music intervention studies have been conducted in neurological and neuropsychiatric conditions. ${ }^{8}{ }^{9}$ Recent genomics studies have suggested that listening to music and music performance affect human gene expression profiles. ${ }^{10}{ }^{11}$ Although much is already known, empirical data is scarce about the biological effects of music on the bodies of professionals or novice musicians.

Being a professional musician in the classical genre requires the musician to control an instrument with a high level of precision, and it is not possible to acquire this level without long-term everyday practice, starting in early childhood. Having a drive for music may be one of the pre-requisites for choosing music as a profession, suggesting that music training is enjoyable and rewarding and offers opportunities to develop as an artist and express artistic skills. Several biological and environmental factors such as genetic background, early detection of an interest towards music, and support from family and society may facilitate this development. ${ }^{12}$ Since professional musicians in the classical genre have an exceptionally 
intense drive and a long exposure to music, we hypothesize that in this group of musicians, the biological effects of music could be most easily detected. In order to obtain more information about the biological effects of music we examined the causes of death among Finnish professional musicians.

\section{Study population and methods}

We investigated two groups of classical professional musicians for the study: 1) Church musicians (church) and 2) Orchestral musicians and performing artists (performers), including musicians working in radio- and television, as independent artists, and as theatre- and opera musicians (see Table 1). The selection of the groups was based, first, on the fact that in these groups musical training usually begins early and continues throughout the musician's lifetime. Secondly, we chose these two groups because the characteristics of the professions differ.

The selection was based on the Finnish classification of professions in Statistics of Finland (www.stat.fi). When selecting the participants, we checked both the occupational category and the standard industrial classification; in addition, we checked the degrees in music obtained by church musicians. Since the position as a performing soloist, in an orchestra, or at the opera is based on audition, we did not check the degree for performers. The work history of the subject covered the years between 1970 and 2016. Since the categorization used in the Statistics of Finland has changed between 1970 and 2016, we chose the following occupational categories for church musicians in the Evangelical-Lutheran and Orthodox Church: 'cantor', 'organist', 'cantor-organist', and 'church musician'; and the following for performers: 'conductor', 'choir conductor', 'singer', 'opera-singer', 'opera-musician', 'choir-singer', 'cellist', 'violinist', 'pianist', 'composer', 'musician or singer in the classical genre'. The whole population of 
Finland (current population 5.5 million inhabitants) during the same time period was chosen as a control group.

We calculated cumulative work years in the study population mentioned above and grouped the individuals according to the first profession in which they had worked for ten years. In the case of a tie, we grouped them first as church musicians and then as performers. The follow-up started when ten years of professional experience had been accumulated and ended in 2016 or on the subject's death which ever occurred first.

We studied the following causes of death using data obtained from the Statistics of Finland (permission TK-52-557-18): cancers (ICD10 C00-C97); neurodegenerative diseases (F01, F03, G30, R54); cardiovascular diseases including ischemic heart diseases (I20-I25), cerebrovascular diseases (I60-I69), and other diseases of the circulatory system (I00-I15, I26I28, I70-I99); and alcohol related diseases and accidental poisoning by alcohol (V01-X44, X46Y89, V01-X44, X46-X59, Y10-Y15, Y85-Y86). More specifically, diagnosis of neurogenerative diseases was based on the most common neurodegenerative diseases of the brain, that is, Alzheimer's disease, Lewy body disease, frontotemporal dementia and multiple systems atrophy (MSA) (see Appendix Table 3).

We calculated all-cause and cause-specific standardized mortality ratios (SMR) assuming a Poisson distribution. ${ }^{13-15}$ Age, sex, and calendar year adjusted SMRs were calculated using the R-language ${ }^{16}$ package popEpi ${ }^{17}$. 


\section{Results}

The study population consisted of 28,148 individuals (56.9\% female) (Table 1$)$. A total of 22 , 368 church musicians and 5,780 performing artists were found who had worked for 10 years or more in their profession. SMR for all-cause mortality was 0.59 (95\% CI: $0.57-0.61)$ for church musicians and 0.75 (95\% CI: $0.70-0.80)$ for performing artists when the study population was compared to general population of Finland (Table 2 and Figure 1). Based on the results, the professional musicians in the classical genre do not represent a homogeneous group. Overall, the SMRs of performing artists were higher than SMRs of church musicians in all diagnostic categories (Table 3).

The analyses of cause-specific SMRs revealed that deaths of alcohol-related diseases were especially rare in church musicians (Table 3). With performing artists, the SMRs were approximately the same as with the general population. (Table 3). When the cause-specific SMRs were analysed separately for females and males, there was an increase in SMR for female performing artists of alcohol-related mortality (SMR 1.85, 95\% CI: 1.06-2.95) compared to that in general population and in church musicians and male performing artists (Table 4 and Figure 1).

For neurodegenerative diseases, no difference was found in SMRs between the church musicians and the general population (Table 3). However, we found that performing artists had a slightly higher SMR of 1.29 (95\% CI: 1.06-1.54) compared to the general population. The increase was seen especially in males (1.46; 95\% CI: 1.13-1.84) (Table 4).

For cardiovascular diseases, SMR was lower among professional musicians compared to the general population (Table 3). Among church musicians the SMR for cardiovascular diseases was higher in females (SMR 0.75; 95\% CI: 0.68-0.82) than in males (SMR 0.58; 95\% CI: 0.54-0.64) (Table 4). For cancers, lower SMRs were identified in both musician groups compared to the 
general population (Table 3). As with cardiovascular diseases, a clear gender difference in SMRs for cancers was detected between female church musicians (SMR 0.90; 95\% CI: 0.83-0.97) and male church musicians (SMR 0.60; 95\% CI: 0.54-0.67). With performing artists, the SMRs were at the same level as those of the female church musicians (Table 4 and Figure 1).

\section{Discussion}

We have performed a comprehensive study about the mortality of professional musicians in the classical genre. The study is related to a wider question about the biological effects of music in general and gives new information about the causes of death of professional musicians. The lower all-cause mortality in professional musicians compared to the general population supports the previous findings ${ }^{189}$ that music has beneficial effects on human health. However, there are some caveats. The SMRs varied depending on profession in the classical genre; church musicians and performing artists differed from each other in several diagnostic categories and gender differences were also common. Below we will discuss each diagnostic category separately, and we begin with comparisons between the study groups and the general population and follow with comparisons between genders within the study group.

\section{Alcohol-related diseases}

There was a clear difference between the SMRs for alcohol-related diseases in church musicians and performing artists. The SMRs for alcohol-related diseases were very low for church musicians. It has been shown that there is a connection between low-level alcohol use and religiousness, especially in rural areas. ${ }^{18}$ With performing artists, by contrast, the mortality rates adjusted for age, sex and calendar year were approximately the same as for the general population (Table 3). It should however be noted that female performing artists had higher SMRs than males (Table 4 and 
Figure 1). Performing artists obtain their work by public auditions and competitions. The work is characterized by constant performances and preparing for them, and the performances are exposed to public critic which may cause stress. The use of alcohol is known to ameliorate anxiety and stress ${ }^{19}$ that are likely to be aggravated with long working hours. ${ }^{20}$ It is known that females are more sensitive to the harmful effects of alcohol than males. ${ }^{21}$ With performing musicians in the classical genre we did not find the increase in deaths of liver diseases, suicides, drug abuse and accidents that has earlier been found among professional musicians in pop music. ${ }^{22}$

According to the current understanding, music and alcohol partially share the same neurocircuits, increase dopamine secretion and mediate the rewarding effects in the brain thus reinforcing each other. Compatible with this, dopamine secretion improves the creative thinking and goal-directed modes of work, ${ }^{23}$ important for performing musicians. There is evidence that the trait of sensationseeking has been associated with increased alcohol misuse in female musican performers of certain genres, including classical, folk, jazz and blues. ${ }^{24}$ The result calls for further study of alcohol use in the group of performing artists.

\section{Neurodegenerative diseases}

Based on our results, the mortality to neurodegenerative diseases is increased in male performing artists in this study (Table 4; Fig.1). Age, common diseases (diabetes, obesity, hypertension, dyslipidemia), genetic liability and life style (alcohol, smoking) are known risk factors for neurodegenerative diseases whereas education, healthy diet, leisure and physical activities protect from them. ${ }^{25}$ In addition, work-related stress has been shown to increase mild cognitive impairment, dementia and Alzheimer disease. ${ }^{26}{ }^{27}$ Musicians go through a number of examinations already during their studies, and the field exposes them to professional competition. Musicians' personal and artistic expectations are high and subjected to public 
critic. The work of performing artists is characterized by an all-encompassing devotion to the profession, and individuals are deeply engaged in their work possibly complicating their social lives due to a lack of time. These stressors combined with irregular working hours (the concerts usually take place in the evenings, disturbing the normal circadian rhythm) in performing artists have been well described; for example, Vervainioti and Alexopoulos ${ }^{28}$ recognized 19 stressors and classified them into seven categories. Adrenocortical activation has an important role in coping with physical and psychogenic stressors and is the risk factor for neuronal damage in hippocampus that affects the memory. ${ }^{27}$ To our knowledge, studies about the effects of music training on brain structure and function are only available for young musicians (average age 25 years). ${ }^{59}$ Increased SMRs for neurodegenerative diseases found in this study raise the question of whether exposure to music really can ameliorate dementia. Again, further studies are warranted concerning the course of events leading to neurodegeneration as well as sex difference for susceptibility to neurodegenerative diseases in performing artists.

\section{Cardiovascular diseases and cancers}

Overall, both the musician groups had lower SMRs for cardiovascular diseases than the general population. Additionally, the church musicians had lower SMRs for cancers. (Table 3.) Cardiovascular diseases and cancers share common risk factors such as age and life-style (diet, harmful use of alcohol, smoking, physical inactivity). ${ }^{30} 31$ In addition to music, these factors may have a favourable effect on the musicians' body but the effect of education cannot be excluded. ${ }^{32}$ It has to be noted that the study groups had a higher education (up to a university degree) and a higher socioeconomic status in their field, and these are known to be associated to lower mortality. ${ }^{33}$ 
Even though church musicians' SMRs for cardiovascular diseases and cancers were lower than those for the general population (Table 3), the results showed clear differences in SMRs between male and female church musicians (4 and Figure 1). Males are usually more susceptible to cardiovascular diseases than females. ${ }^{34}$ Interestingly, in in this study female church musicians had higher SMR than males. Similar gender difference was obtained also with cancers. These differences cannot be explained by the work as such. There is some evidence that female musicians might be more conscientious than males ${ }^{32}$ and thus more sensitive to public opinion. Church musicians have also unconventional working hours and work fragmentation, ${ }^{35}$ which restrict every-day life more in female than male church musicians and cause abnormal day rhythms that are known to increase morbidity. ${ }^{3637}$ Additionally, exogenous stressors are known to influence mood and cardiovascular regulation. ${ }^{38}$

We acknowledge several limitations in this study. First, professional musicians in this study may have been working in different positions during their lives. It is possible that especially the performing artists have been categorized into the occupational category of music teachers and were hence not found in our study. In addition, no information was available about the musical practices of individuals in the control group. Further, the diagnostic criteria of neurodegenerative diseases have been developed during the study period and may not be the same for all cases. In an observational study, it is not possible to determine if associations are really due to exposure, in this study occupational category, or if there are confounding factors causing association. It is quite possible that there is selection bias in this study. This means that there are several characteristics connected to personal and other characteristics of musician that determine to which group he or she will belong. These same unmeasured characteristics may also be connected to mortality. 


\section{Conclusions}

Our study was the first one to examine causes of death in musicians of the classical genre. The strengths of our study are the whole Finnish cohort of church musicians and performing artists working between 1970 and 2016 as well as the ICD-10-based causes of deaths.

Although cardiovascular diseases, cancers, and neurodegenerative diseases share many common risk factors, our results showed higher SMRs for neurodegenerative diseases than for the other two diagnostic groups in professional musicians. This may suggest that the brain is sensitive to environmental effects, such as stress. Our results indicate that the effect of performance-related stress may contribute to the overall higher SMRs of performing artists in all diagnostic categories compared to the church musicians and the differences between male and female musicians.

Music can be considered as an environmental enrichment ${ }^{39}$ that improves brain function. ${ }^{3467}$ In this study, this effect could not be demonstrated; instead, it seems that there are other factors in musicians' profession, for example performance-related stress that may have contributed to the differences in SMRs between male and female musicians of our study. The results can be used to inform health care professionals, musicians, and music students about the risk factors.

Acknowledgements The authors thank The Statistics of Finland for giving their data for the analysis. 
Contributors TK designed the study, selected the study material and wrote the manuscript. JH performed the statistical analyses and wrote the manuscript. LM advised the study design. IJ got the idea for the study, selected the diagnoses, and wrote the manuscript. All authors approved the final version of the manuscript.

Competing interests None declared.

Patient consent Not required.

Funding The University of the Arts, Helsinki, provided the funding for the study.

\section{References}

1. Sutoo D, Akiyama K. Music improves dopaminergic neurotransmission: demonstration based on the effect of music on blood pressure regulation. Brain Res 2004; 1016:255262. DOI:10.1016/j.brainres.2004.05.018

2. Salimpoor VN, Benovoy M, Larcher K, Dagher A, Zatorre RJ. Anatomically distinct dopamine release during anticipation and experience of peak emotion to music. Nat Neuroscience 2011;14:257-62. DOI:10.1038/nn.2726

3. Herholz SC, Zatorre RJ. Musical training as a framework for brain plasticity: behavior, function, and structure. Neuron 2012; 76: 486-502. doi: 10.1016/j.neuron.2012.10.011

4. Sluming V, Brooks J, Howard M, Downes JJ, Roberts N. Broca's Area Supports Enhanced Visuospatial Cognition on Orchestral Musicians. J Neuroscience 2007;27(14): 3799-3806. DOI:10.1523/JNEUROSCI.0147-07.2007

5. Gaser C, Schlaug G. Brain Structures Differ between Musicians and Non-Musicians. $J$ Neuroscience 2003; 23(27): 9240-9245.

6. Zatorre RJ, Chen JL, Penhune VB. When the brain plays music: auditory-motor interactions in music perception and production. Nat Rev Neuroscience 2007; 8(7): $547-$ 58. DOI: $10.1038 / \mathrm{nrn} 2152$

7. Flaugnacco E, Lopez L, Terribili C, Montico M, Zoia S, Schön D. Music training increases phonological awareness and reading skills in developmental dyslexia: a randomized control trial. PLOS ONE 2015;10:e0138715. doi: 10.1371/journal.pone.0138715

8. Särkämö T, Tervaniemi M, Laitinen S, et al. Music listening enhances cognitive recovery and mood after middle cerebral artery stroke. Brain 2008;131: 866-76.doi: $\underline{10.1093 / \mathrm{brain} / \mathrm{awn} 013}$

9. Sihvonen AJ, Särkämö T, Leo V, Tervaniemi M, Altenmüller E, Soinila S. Music-based interventions in neurological rehabilitation. The Lancet Neurology 2017;16(8): 648-660. DOI: $10.1016 / \mathrm{S} 1474-4422(17) 30168-0$ 
10. Kanduri C, Raijas P, Ahvenainen M, Philips AK, Ukkola-Vuoti L, Lahdesmaki H, Järvelä I. The effect of listening to music on human transcriptome. PeerJ 2015; 3:e830. DOI: $10.7717 /$ peerj. 830

11. Kanduri C, Kuusi T, Ahvenainen M, Philips AK, Lahdesmaki H, Jarvela I. The effect of music performance on the transcriptome of professional musicians. Scientic Reports 2015;5: 9506. DOI:10.1038/srep09506

12. Oikkonen J, Huang Y, Onkamo P, et al. A genome-wide linkage and association study of musical aptitude identifies loci containing genes related to inner ear development and neurocognitive functions. Molecular Psychiatry 2015; 210(2): 275-82.

DOI: $10.1038 / \mathrm{mp} .2014 .8$

13. Hakulinen T, Seppä K, Lambert PC. Choosing the relative survival method for cancer survival estimation. Eur J Cancer 2011; 47: 2202-10. DOI:10.1016/j.ejca.2011.03.011

14. Pohar PM, Janez S, Jacques E. On Estimation in Relative Survival. Biometrics 2012; 68:113-20.https://onlinelibrary.wiley.com/doi/abs/10.1111/j.1541-0420.2011.01640.x

15. Seppä K, Hakulinen T, Pokhrel A. Choosing the net survival method for cancer survival estimation. Eur J Cancer 2015; 51: 1123-9. DOI:10.1016/j.ejca.2013.09.019

16. R Core Team. R: A Language and Environment for Statistical Computing. Vienna, Austria: R Foundation for Statistical Computing. 2016. URL http://www.R-project.org/.

17. Miettinen J, Rantanen M. popEpi: Functions for Epidemiological Analysis using Population Data. 2017.

18. Winter T, Karvonen S, Rose RJ. Does religiousness explain regional differences in alcohol use in Finland? Alcohol and Alcoholism 2002;37(4): 330-339.

19. Silberman Y, Bajo M, Chappell AM, et al. Neurobiological Mechanisms Contributing to Alcohol-Stress-Anxiety Interactions. Alcohol 2009; 43(7): 509-519.

DOI:10.1016/j.alcohol.2009.01.002

20. Virtanen M, Jokela M, Solja T, et al. Long working hours and alcohol use: Systematic review and meta-analysis of published studies and unpublished individual participant data. $B M J$ 2015; 350. doi: https://doi.org/10.1136/bmj.g7772

21. Li TK, Beard JD, Orr WE, et al. Gender and ethnic differences in alcohol metabolism. Alcohol Clin Exp Res 1998; 22(3):771-772.

22. Kenny DT, Asher A. Life Expectancy and Cause of Death in Popular Musicians: Is the Popular Musician Lifestyle the Road to Ruin? Medical Problems of Performing Artists 2016; 31(1): 37-44. doi: 10.21091/mppa.2016.1007

23. Flaherty AW. Brain Illness and Creativity: Mechanisms and Treatment Risks. The Can J Psychiatry 2011;56(3): 132-143. DOI:10.1177/070674371105600303

24. Miller KE \& Quigley BM. Sensation-seeking, performance genres and substance use among musicians. Psychology of Music 2011; 40 (4):389 - 410. doi.org/10.1177/0305735610387776

25. Mayeux R \& Stern Y. Epidemiology of Alzheimer Disease. Cold Spring Harb Perspect Med 2012;2(8): a006239. DOI:10.1101/cshperspect.a006239

26. Sindi S, Hagman G, Håkansson K, et al, Midlife Work-Related Stress Increases Dementia Risk in Later Life: The CAIDE 30-Year Study. The Journals of Gerontology. Series B, Psychological sciences and social sciences 2017; 72(6): 1044-1053. DOI: $10.1093 /$ geronb/gbw043 
27. Caruso A, Nicoletti F, Mango D, Saidi A, Orlando R, Scaccianoce S. Stress as risk factor for Alzheimer's disease. Pharmacol Res 2018;22: 130-134.

DOI:10.1016/j.phrs.2018.04.017

28. Vervainioti A, Alexopoulos EC. Job-Related Stressors of Classical Instrumental Musicians: A Systematic Qualitative Review Medical Problems of Performing Artists 2015;4: 197-202. doi: 10.21091/mppa.2015.4037

29. Schlaug G. Musicians and music making as a model for the study of brain plasticity. Prog Brain Res 2015;217: 37-55. doi: 10.1016/bs.pbr.2014.11.020.

30. Tzoulaki I, Elliott P, Kontis V, Ezzati M. Worldwide Exposures to Cardiovascular Risk Factors and Associated Health Effects. Circulation 2016;133:2314-2333.

DOI:10.1161/CIRCULATIONAHA.115.008718

31. Golemis EA, Scheet P, Beck TN, Scolnick E, Hunter DJ, Hawk E, Hopkins N. Molecular mechanisms of the preventable causes of cancer in the United States. Genes Dev 2018; 32(13-14):868-902. DOI:10.1101/gad.314849.118

32. Corrigall KA, Schellenberg EG, Misura NM. 2013. Music training, cognition, and personality. Front in Psychol 2013; 4:222. DOI:10.3389/fpsyg.2013.00222

33. Tarkiainen L, Martikainen P, Laaksonen M, Valkonen T. Trends in life expectancy by income from 1988 to 2007: decomposition by age and cause of death. J Epidemiol Comm Health 2012; 66: 573-8. doi: 10.1136/jech.2010.123182.

34. Appelman Y, van Rijn BB, Ten Haaf ME, Boersma E, Peters SA. Sex differences in cardiovascular risk factors and disease prevention. Atherosclerosis 2015;241(1):211-8. DOI:10.1016/j.atherosclerosis.2015.01.027

35. Niemelä K. Papisto ja kanttorit 2010. Akavan kirkollisten ammattijärjestöjen jäsenkysely raportti. Kirkon tutkimuskeskuksen www-julkaisuja 20. Tampere: Kirkon tutkimuskeskus. 2010. In Finnish.

36. Bailey M, Silver R. Sex Differences in Circadian Timing Systems: Implications for Disease. Front in Neuroendocrinol 2014; 35(1): 111-139. doi: 10.1016/j.yfrne.2013.11.003.

37. Lin X, Chen W, Wei F, Ying M, Wei W, Xie X. Night-shift work increases morbidity of breast cancer and all-cause mortality: a meta-analysis of 16 prospective cohort studies. Sleep Med 2015;16(11):1381-1387. doi: 10.1016/j.sleep.2015.02.543

38. Grippo AJ, Johnson AK. Stress, depression, and cardiovascular dysregulation: A review 11 of neurobiological mechanisms and the integration of research from preclinical disease 12 models. Stress 2009;12(1): 1-21. doi: 10.1080/10253890802046281

39. Lupien SJ, McEwen BSG, Megan R., Heim C. Effects of stress throughout the lifespan on the brain, behaviour and cognition. Nat Rev Neurosci 2009;10:434.

DOI: $\underline{10.1038 / \text { nrn2639 }}$ 


\section{Figures and tables}

Figure 1. Standardized mortality ratios (SMR) and 95\% confidence intervals of four causes of death, separately for males and females in the two study groups.

\section{SMRs and confidence intervals}

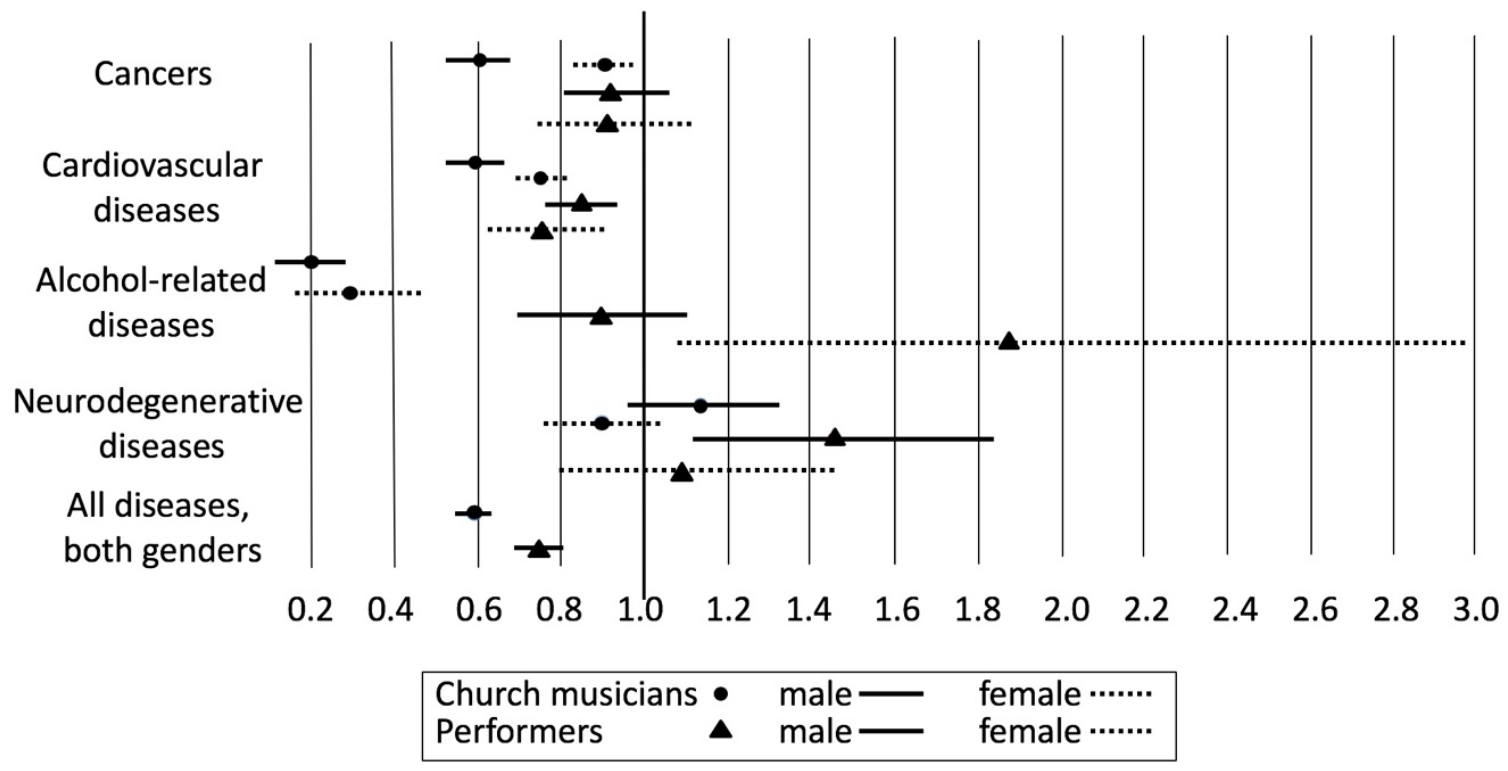


Table 1. Basic characteristics of the study population at the start of the follow-up.

\begin{tabular}{|l|l|r|r|r|}
\hline & & \multicolumn{1}{c|}{ Church } & \multicolumn{1}{c|}{ Performers } & \multicolumn{1}{c|}{ All } \\
\hline Sex & Male & $8348(37.3 \%)$ & $3780(65.4 \%)$ & $12128(43,1 \%)$ \\
\hline & Female & $14020(62.7 \%)$ & $2000(34.6 \%)$ & $16020(56.9 \%)$ \\
\hline & All & $22368(100 \%)$ & $5780(100 \%)$ & $28148(100.0 \%)$ \\
\hline $\begin{array}{l}\text { Age in start of } \\
\text { follow-up }\end{array}$ & 40 or under & & & \\
\hline & $40 \leq 50$ & $9434(42.2 \%)$ & $2774(48.0 \%)$ & $12208(43.4 \%)$ \\
\hline & $50 \leq 60$ & $4890(21.9 \%)$ & $896(15.5 \%)$ & $5786(20.6 \%)$ \\
\hline & over 60 & $1640(7.3 \%)$ & $436(17.5 \%)$ & $2076(7.4 \%)$ \\
\hline & All & $22368(100 \%)$ & $5780(100 \%)$ & $28148(100 \%)$ \\
\hline
\end{tabular}


Table 2. Observed and expected number of deaths and standardized mortality ratios (SMR) with $95 \%$ confidence interval. Comparison to general population of Finland.

\begin{tabular}{|l|r|r|r|r|r|}
\hline Category & \multicolumn{1}{|c|}{ Observed } & Expected & \multicolumn{2}{|c|}{ SMR } & \multicolumn{2}{|c|}{$95 \% \mathrm{Cl}$} \\
\hline Church & 2336 & 3961 & 0.59 & 0.57 & 0.61 \\
\hline Performers & 939 & 1255 & 0.75 & 0.70 & 0.80 \\
\hline
\end{tabular}


Table 3. Observed and expected number of deaths in four diagnostic groups and standardized mortality ratios (SMR) with 95\% confidence interval. Comparison with the general Finnish population and adjusted for age, sex, and calendar year. The SMRs and confidence intervals that differ from the general population are in bold print.

\begin{tabular}{|l|l|r|r|r|r|r|}
\hline \multicolumn{1}{|c|}{ Cause of death } & \multicolumn{1}{c|}{ Category } & Observed & \multicolumn{1}{c|}{ Expected } & \multicolumn{1}{c|}{ SMR } & \multicolumn{2}{|c|}{ 95\% CI } \\
\hline \multirow{2}{*}{ Cancers } & Church & 954 & 1261 & $\mathbf{0 . 7 6}$ & $\mathbf{0 . 7 1}$ & $\mathbf{0 . 8 1}$ \\
\cline { 2 - 7 } & Performers & 334 & 361 & 0.93 & 0.83 & 1.03 \\
\hline \multirow{2}{*}{$\begin{array}{l}\text { Neurodegenerative } \\
\text { diseases }\end{array}$} & Church & 317 & 317 & 1.00 & 0.89 & 1.11 \\
\cline { 2 - 7 } & Performers & 109 & 85 & $\mathbf{1 . 2 9}$ & $\mathbf{1 . 0 6}$ & $\mathbf{1 . 5 4}$ \\
\hline $\begin{array}{l}\text { Cardiovascular } \\
\text { diseases }\end{array}$ & Church & 1017 & 1558 & $\mathbf{0 . 6 5}$ & $\mathbf{0 . 6 1}$ & $\mathbf{0 . 6 9}$ \\
\cline { 2 - 7 } & Performers & 419 & 510 & $\mathbf{0 . 8 2}$ & $\mathbf{0 . 7 5}$ & $\mathbf{0 . 9 0}$ \\
\hline $\begin{array}{l}\text { Alcohol-related } \\
\text { diseases }\end{array}$ & Church & 48 & 211 & $\mathbf{0 . 2 3}$ & $\mathbf{0 . 1 7}$ & $\mathbf{0 . 3 0}$ \\
\cline { 2 - 7 } & Performers & 77 & 79 & 0.98 & 0.78 & 1.21 \\
\hline
\end{tabular}


Table 4. Sex-specific observed and expected number of deaths in four diagnostic groups and standardized mortality ratios (SMR) with $95 \%$ confidence interval. Comparison to the general Finnish population and adjusted for age, sex, and calendar year. The SMRs and confidence intervals that differ from the general population are in bold print.

\begin{tabular}{|c|c|c|c|c|c|c|c|}
\hline Cause of death & Category & Sex & Observed & Expected & SMR & \multicolumn{2}{|c|}{$95 \% \mathrm{Cl}$} \\
\hline \multirow{4}{*}{$\begin{array}{l}\text { Cancers } \\
\text { ICD10 C00-C97 }\end{array}$} & Church & male & 365 & 604 & 0.60 & 0.54 & 0.67 \\
\hline & Church & female & 589 & 657 & 0.90 & 0.83 & 0.97 \\
\hline & Performers & male & 243 & 262 & 0.93 & 0.81 & 1.05 \\
\hline & Performers & female & 91 & 99 & 0.92 & 0.75 & 1.13 \\
\hline \multirow{4}{*}{$\begin{array}{l}\text { Neurodegenerative } \\
\text { diseases } \\
\text { F01, F03, G30, R54 }\end{array}$} & Church & male & 146 & 126 & 1.16 & 0.98 & 1.36 \\
\hline & Church & female & 171 & 191 & 0.89 & 0.77 & 1.03 \\
\hline & Performers & male & 66 & 45 & 1.46 & 1.13 & 1.84 \\
\hline & Performers & female & 43 & 39 & 1.09 & 0.80 & 1.45 \\
\hline \multirow{4}{*}{$\begin{array}{l}\text { Cardiovascular } \\
\text { diseases } \\
100-115,120-125, \\
126-128,160-169, \\
170-199\end{array}$} & Church & male & 529 & 906 & 0.58 & 0.54 & 0.64 \\
\hline & Church & female & 488 & 653 & 0.75 & 0.68 & 0.82 \\
\hline & Performers & male & 322 & 383 & 0.84 & 0.75 & 0.94 \\
\hline & Performers & female & 97 & 127 & 0.76 & 0.62 & 0.92 \\
\hline \multirow{4}{*}{$\begin{array}{l}\text { Alcohol-related } \\
\text { diseases V01-X44, } \\
\text { X46-Y89, V01-X44, } \\
\text { X46-X59, Y10-Y15, } \\
\text { Y85-Y86 }\end{array}$} & Church & male & 29 & 145 & 0.20 & 0.14 & 0.28 \\
\hline & Church & female & 19 & 66 & 0.29 & 0.18 & 0.44 \\
\hline & Performers & male & 62 & 71 & 0.88 & 0.68 & 1.12 \\
\hline & Performers & female & 15 & 8 & 1.85 & 1.06 & 2.95 \\
\hline
\end{tabular}

